\title{
湾 \\ Scaffolding as a metaphor in disciplinary content and in multimedia architecture: A CD-ROM on Building Understandings in Literacy and Teaching
}

\author{
Kristina Love \\ The University of Melbourne
}

\begin{abstract}
This paper outlines key decisions that were made in the design of a multimedia resource (a CD-ROM entitled 'BUILT') that develops preservice teachers' understandings about language, literacy and teaching. A major consideration in the design process was that the concept of scaffolding, central to the instructional content regarding learning and teaching through language, should also be operationalised in the instructional design of the CD-ROM. A second consideration was that preservice teachers be provided with authentic materials for observation, analysis and reflection and thus the operating structure of the CD-ROM conforms to the conditions for situated learning. A final consideration was that the hypermedia form of the resource be suitable to meet the needs of a variety of cohorts of users.
\end{abstract}

\section{Background and introduction to BUILT}

A Project of National Significance on the Preservice Preparation of Teachers for Teaching English Literacy (Christie et al, 1991, Vol 1: 98) made an important recommendation that 'as a compulsory component of their preservice education, all teachers should receive a substantial preparation in knowledge about language and literacy and the pedagogical principles for their teaching'. For nearly a decade, this recommendation had been implemented in the preservice preparation of students in the Faculty of Education at the University of Melbourne through the teaching of a subject called 'Language and Literacy in the Classroom'. This subject was compulsory for all preservice students in the Diploma of Education and Bachelor of Teaching courses, regardless of which discipline they were preparing to teach, whether this be English, LOTE, Music, Maths, Science, SOSE (Study of Society and Environment) or Arts.

Over this decade, various textbook based programs had been trialled and found wanting in their capacity to fully engage preservice teachers in building their understandings about language, literacy and teaching across 
the curriculum. Various combinations of workshop/lecture approaches, essentially based on reading packs with additional video resources, could not create the motivating and active learning environment sought by the course designers. A particular challenge was to make vivid for these preservice teachers, the classroom contexts in which their developing knowledge about language and its relationship to learning could be applied. This challenge was compounded by the fact that only 18 contact hours were available for a subject in which over 800 students were enrolled in 2001. Clearly, a radical alteration was required in the provision of key resources that would engage developing teachers and maximise their learning in a 'mass delivery' and time restricted course. The course designers applied for and received a small internal grant to develop a CDROM which could provide innovative video based and interactive materials displaying authentic learning of and through language and literacy. This CD-ROM, 'Building Understandings in Literacy and Teaching' (BUILT) would be flexible enough to be used in a variety of modes, including lectures, workshops and independently by students.

BUILT was thus developed in an environment of mass education, of timerestricted face to face teaching and of diminishing resources in a period of economic restraint, an environment currently typical of the tertiary sector as a whole (Sheely, Veness \& Rankine, 2001). Working with these constraints, BUILT's designers were motivated to produce a resource that was principled in its model of language and literacy, authentic in its representation of teaching and learning with language, and coherent in its means of guiding developing teachers through unfamiliar disciplinary content. Each of these motivations will be discussed separately below.

The model of language and literacy underpinning BUILT is a functionally oriented one, concerned with how meanings are made in real social and cultural contexts where language serves a variety of purposes (Halliday, 1973, 1994; Derewianka, 1990, 1998). Users of the CD learn about the structures and functions of the English language in its written and spoken forms as they observe language being used to learn in a range of classroom contexts and as they learn how to apply this linguistic knowledge to their own teaching contexts. BUILT makes extensive use of high quality QuickTime video clips of exemplary classroom interactions that illustrate how a wide variety of strategies operate to achieve the desired language and literacy outcomes. BUILT thus grounds key concepts about language, literacy and pedagogy in the virtual experience of actual classroom interactions.

The authenticity of the QuickTime video resources clearly contributes to a higher level of preservice teachers' engagement with principles of language 
and learning than those afforded by other forms of text based materials used in previous years. In particular, BUILT as a multimedia resource provides the opportunity for developing teachers to freeze and systematically reflect on the language of classroom interactions in ways that are not possible in the real context, a feature valued highly in user feedback in a formal evaluation of the CD. A notepad facility allows users to record reflections on these 'frozen moments' and respond to key questions, both of which can be saved to floppy disk, a hard drive or a server, while still using the CD-ROM. QuickTime video (QTV) clips of teacher interviews provide further insights into teachers' planning, teaching and assessment decisions and how these impact on their students' language and literacy development.

\section{The context in which BUILT was used}

BUILT was first used in semester one, 2001 at the University of Melbourne, with 800 students purchasing and using the resource in the subject 'Language and Literacy in the Classroom' and using it as a major component of their preparation for and reflection on, workshops, teaching experience, and assessment. A significant minority of these preservice teachers (the average age the previous year was 35) had little experience with computer technology in general and most had no experience with educational CD-ROMs in particular. BUILT was the key resource used to help students achieve the learning outcomes of the subject 'Language and Literacy in the Classroom', these being that students:

- develop an initial understanding of the basic structures and functions of oral and written language

- identify how oral and written language contribute to learning in a variety of classroom interactions

- reflect on and share understandings about the role of language in learning across discipline areas and year levels

- formulate the ways in which their own teaching can benefit from their knowledge about language and its relationship to learning.

For the one semester duration of the subject, students were encouraged to use BUILT in three separate, but integrated contexts. In workshop groups, they observed and discussed the QTVs of classroom interactions and teacher interviews, as these were selected by teacher educators who used data projection trolleys in specially designed 'collaborative teaching' spaces. A regular outcome of such collaborative workshops was that preservice teachers from different disciplinary backgrounds could identify key features of spoken and written language as these were used for learning in various contexts. As well as working collaboratively, students 
were also encouraged to use BUILT independently as they selected QTVs relevant to their particular discipline areas and needs. The intention here was for students to rehearse specific features of their own language and literacy use before their practice teaching rounds. The majority of students used the product independently on their home computers, with about one quarter using it in faculty computer labs. A third way in which students were encouraged to use BUILT was with a peer, as a means of reviewing the pedagogical decisions they made during or after their practice teaching rounds. Such paired interactions regularly took place in computer labs at the University or at the school in which teaching practice was taking place.

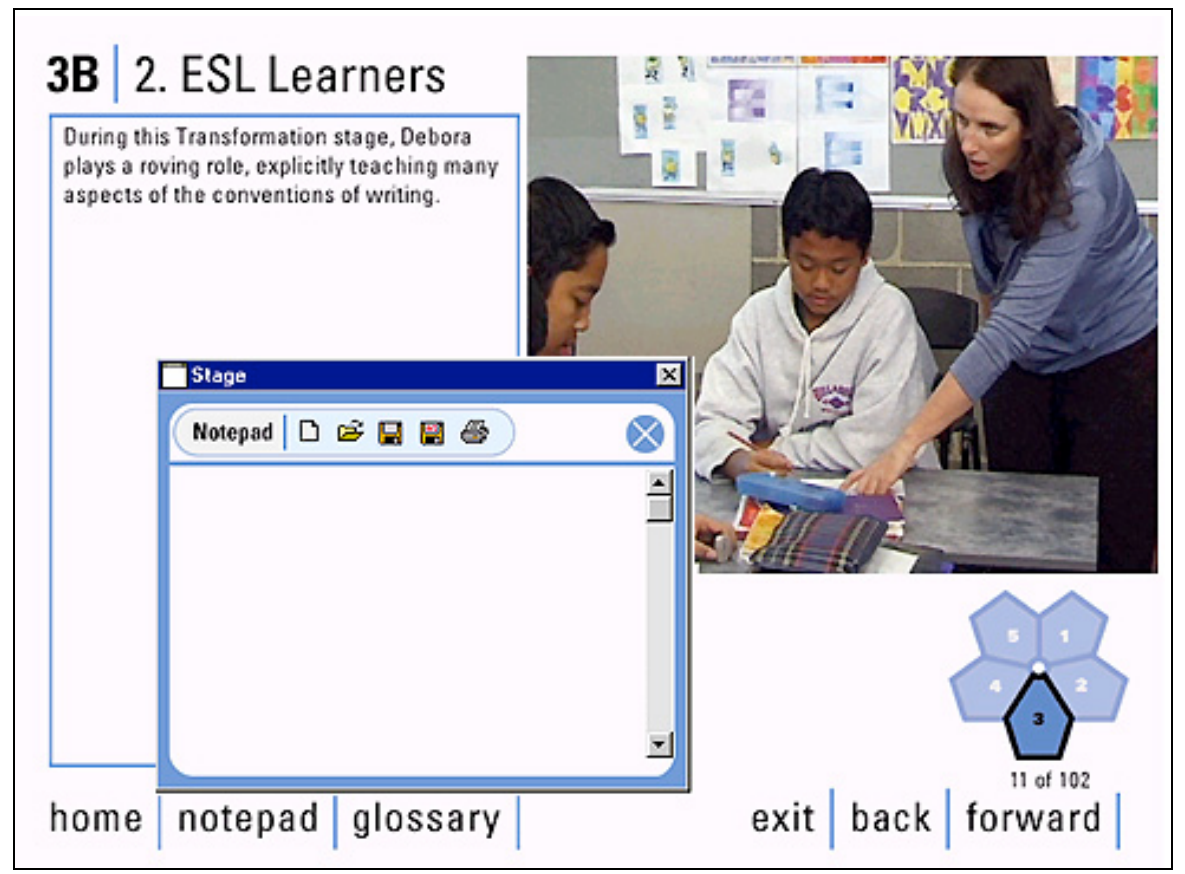

Screenshot 1: ESL learners

Workshop activities were enriched by students bringing responses recorded independently in the notepad facility built into the CD. Assessment was also enriched through the notepad and the shared reflections, allowing valid demonstration of students' developing capacities to learn content knowledge about language and pedagogy based on authentic materials, while developing their own language and literacy skills. 
In these 'situated' (Brown, Collins and Duguid, 1989; Lave and Wenger, 1991) ways, and using authentic texts, preservice were systematically apprenticed into becoming 'insiders' (Kramsch, 1998) in the discourse community of reflective professional educators (Schon, 1983). In addition, Panoramic QuickTime Virtual Reality screens with numerous hotspots allowed users to explore the written language of a number of classroom environments and consider the quality and range of resources for scaffolding students in these contexts. All texts presented and analysed in the CD-ROM are authentic in the sense that they are either produced or read by real teachers and students. These texts were vehicles for guided analysis and interactive exercises, allowing the teaching and learning about language and literacy to be more practically oriented. Through the use of QuickTime Video clips of classroom interactions and teacher reflections, the QTVRs and the interactive tasks with authentic texts in a range of contexts, and through the guidance of the notepad facility, developing teachers were provided with rich opportunities to systematically examine the language used in a range of classrooms as specific discourse communities.

\section{B 1 1. Early Primary}

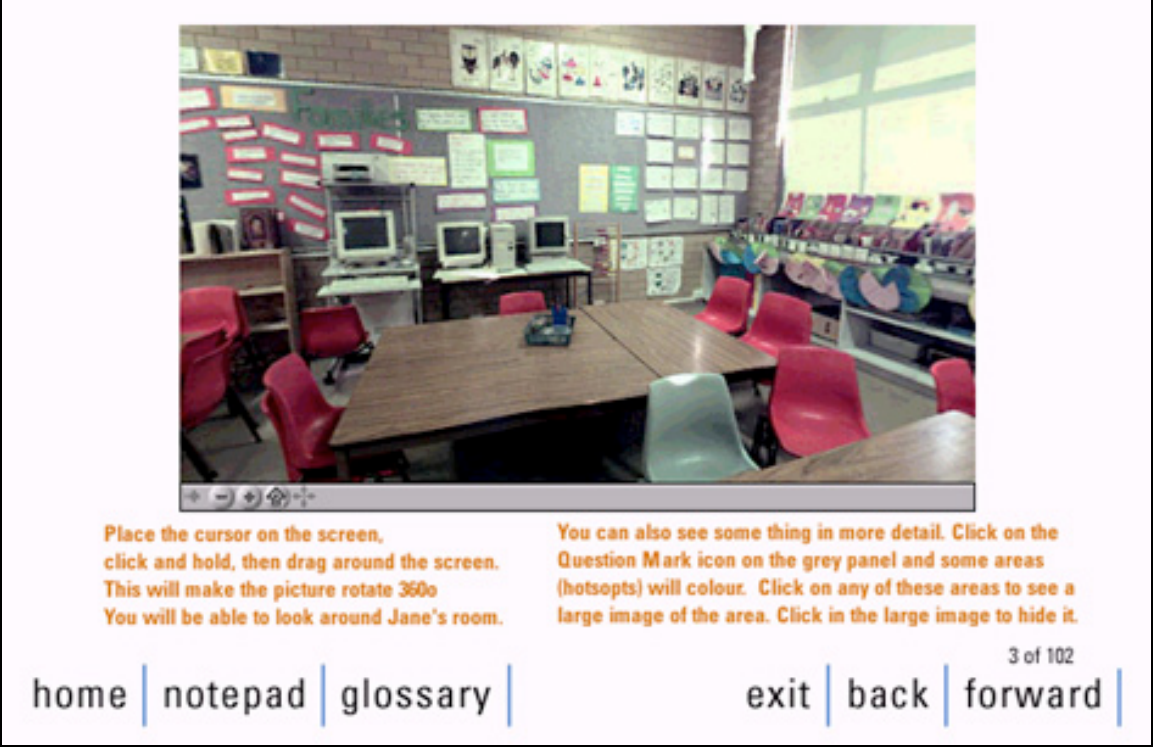

Screenshot 2: Early primary 
Structuring the CD-ROM to guide preservice teachers through unfamiliar disciplinary content was the most significant challenge facing the designers. While BUILT provided models of the ways in which the modes of speaking, listening, reading and writing were integrated in classroom teaching and learning, it was also important to throw a spotlight on each of these modes in isolation to help sharpen novice teachers' awareness of the distinctive contribution of each mode to learning. A decision was made to structure BUILT into four Units, entitled respectively 'Texts in Context'; 'Oral Language'; 'Writing' and 'Reading'. These units were each divided into two topics, the first being an examination of the structures and functions of language in each mode and the second being an examination of teachers scaffolding learning through each mode.

Because of the 'hierarchical' nature of the hypermedia linking (Oliver \& Herrington, 1995), users could enter the CD-ROM at any unit or topic, depending on their teaching area, their teaching level and their existing knowledge about language. However, the key subject in which BUILT was used in 2001, 'Language and Literacy in the Classroom' was structured such that students (most of whom had little knowledge about language) would progress in a sequential manner by looking at one topic in each week of a nine week course. Because of the institutional demands on this subject (dealing as it did with large numbers of students of mixed abilities) and because of the unfamiliar and potentially complex nature of the content, a referential form of hypermedia (Oliver \& Herrington, 1995), where learners are free to move between associated nodes with little structure being evident, was not seen as appropriate as a hyperlinking structure.

Once the basic hypermedia form was decided, decisions still had to be made about how to scaffold users within each of the four units and eight topics, through complex and new information about the structures and functions of spoken and written texts. Tools such as a Glossary button allowed users to check their understanding of linguistic terminology at point of need and a Bibliography button allowed them to access a list of selected references. An important consideration in structuring user pathways through this information was that users should simultaneously be able to reflect on how they could scaffold their own students into learning through these modes. Interactive features such as animations, transcripts accompanying video clips, drag and drop, and roll over facilities were designed to deepen novice teachers' understandings of classroom interactions, to rehearse emerging content knowledge, in particular unfamiliar features of language, and to present that knowledge in workshops and assignments. 
These tools and interactive features provided some scaffolding for users new to content about language, literacy and the classroom applications of these. However there remained the challenge of providing users with a coherent pathway as they are immersed in the language, behaviours, culture and chaos of 'real' classrooms. The central metaphor of scaffolding was thus conceptualised in such a way that it informed both the instructional content and the fundamental organising principle in the design of BUILT. The remainder of this paper will focus on the ways in which the metaphor of scaffolding was developed as a major element of the CD-ROM at both these levels.

\section{Scaffolding as instructional content}

In concrete terms, scaffolding refers to the structures that are erected around buildings which are either being constructed or repaired. These structures allow workers to establish the building until such time as it can support itself, at which point the scaffolding is removed. Although it has some obvious limitations, the metaphor of scaffolding is a valuable one for describing the temporary supporting structures provided by teachers as they assist learners to develop new understandings and skills. Importantly, the metaphor captures both the centrality of the teacher's withdrawal of support as learners develop control over specific understandings and skills, and the erection of further scaffolding to support the development of a new set of specific understandings and skills.

The concept of scaffolding was originally used by Wood, Bruner \& Ross (1976) to portray the temporary, but essential nature of parental support in the language development of young children. This concept has proved to be attractive in socio-cultural models of learning in general (Mercer, 1994) and of language learning in particular (Halliday, 1973, 1994). This sociocultural model posits that cognitive development is not simply influenced by social processes, but is profoundly grounded in social and cultural processes. It is this theoretical model of learning which underpins the instructional content of BUILT. Given the 'intersubjective' foundations of learning (Bruner, 1986), teachers at all levels have a profound responsibility for organising the social processes of their classrooms to maximise learning.

Wood, Bruner \& Ross's (1976) concept of scaffolding has since been used extensively in the educational literature and in a variety of institutional contexts, though it is often used very loosely to refer to any sort of teaching or helping of learners. Calls for a more precise definition of the term have been made across various educational sectors, in particular those to do with early literacy development (Maybin, Mercer \& Stierer, 1992; 
Hammond, 2001) and those concerned with multimedia development (Herrington \& Oliver, 1997; McLoughlin et al, 2000; Winnips et al, 2000). Most recently in the area of literacy education, three key factors have emerged as distinguishing scaffolding from other forms of teaching (Maybin, Mercer \& Stierer, 1992).

1. The task, skill, or understanding being scaffolded is a specific learning activity with finite goals. One criterion for judging whether help can be considered as scaffolding is evidence that the teacher intends for a learner to develop a specific skill, grasp a particular concept, or achieve a particular level of understanding and plans accordingly.

2. Scaffolding is help that will enable a learner to accomplish a task, skill or understanding which they would not quite have been able to manage on their own. Thus scaffolding involves the teacher determining what skill or understandings learners currently have, in order to help them build on those skills and understandings in positive and constructive ways. Vygotsky's (1978:86) notion of the Zone of Proximal Development (ZPD) is implicated here as:

... the distance between the actual development level (of the learner) as determined by independent problem solving and the level of potential development as determined through problem solving under adult guidance or in collaboration with more capable peers.

Scaffolding thus requires the identification of a 'gap' in students' understandings and the construction of ways of helping learners bridge that gap and move into a new ZPD.

3. Scaffolding is intended to bring learners closer to a state of competence which will enable them eventually to complete the task on their own. It involves the teacher structuring the learning activity such that her/his own expertise can be gradually withdrawn till the learner or 'apprentice' can complete the task independently. If there is evidence of the learner having achieved some greater level of independent competence as a result of the help, then that help can be considered as scaffolding.

These three principles of scaffolding are explicitly outlined in the instructional content of BUILT to help pre-service teachers identify how structural support through language occurs, in the exemplary practice represented in the QuickTime video clips, and in the other authentic resources presented. Given its origins in early language development, the concept of scaffolding is particularly powerful in describing how language contributes to student learning through the skilful interventions of teachers, both at primary and secondary school levels and across each of 
the Key Learning Areas. Even more powerful is the use of multimedia to situate this understanding of the concept of scaffolding in virtual representations of real classrooms and of interviews with teachers consciously working with this notion of scaffolding.

Based on these key features of scaffolding, a five stage 'learning/teaching cycle' was developed which would allow preservice teachers (themselves 'apprentice' teachers) to more systematically examine the skilled language and literacy practices of experienced teachers, which are modelled in the video clips. This five stage cycle is graphically represented in the form of a series of pentagons, where each pentagon represents a single learning/ teaching cycle which combines with others to form a cumulative curriculum.

1. Engagement is the stage where the teacher identifies a 'gap' in students' understandings, plans strategies to bridge the gap and engages with learners' prior understandings.

2. Building knowledge is the stage where the teacher provides learners with new information, so that together, teacher and students work towards building 'common knowledge' (Edwards \& Mercer, 1987) and shared understandings of the purpose of the set tasks.

3. Transformation is the stage where learners are provided with opportunities to build their own insights about the new information, the teacher helping as needed and controlling possibilities of error, but judiciously withdrawing help as appropriate.

4. Presentation is the stage where the teacher provides opportunities for learners to complete the task independently and to demonstrate, either formally or informally, their understandings.

5. Reflection is the stage where the teacher and learners reflect on information, insights and understandings and together identify a new 'gap'.

This five stage model of the learning/teaching cycle was robust enough both to reflect the exemplary classroom practice captured on the QuickTime video clips and to be compatible with the socio-cultural/sociocognitive model of learning (Halliday, 1973, 1994; Derewianka, 1990, 1998) that underpinned the instructional content. In particular, it focussed on a view of the classroom as a profoundly social situation; of learning as occurring through intersubjective understandings; of texts in context being seen through a social critical perspective; of learning as occurring through a series of approximations; and of scaffolding as central to effective learning. 


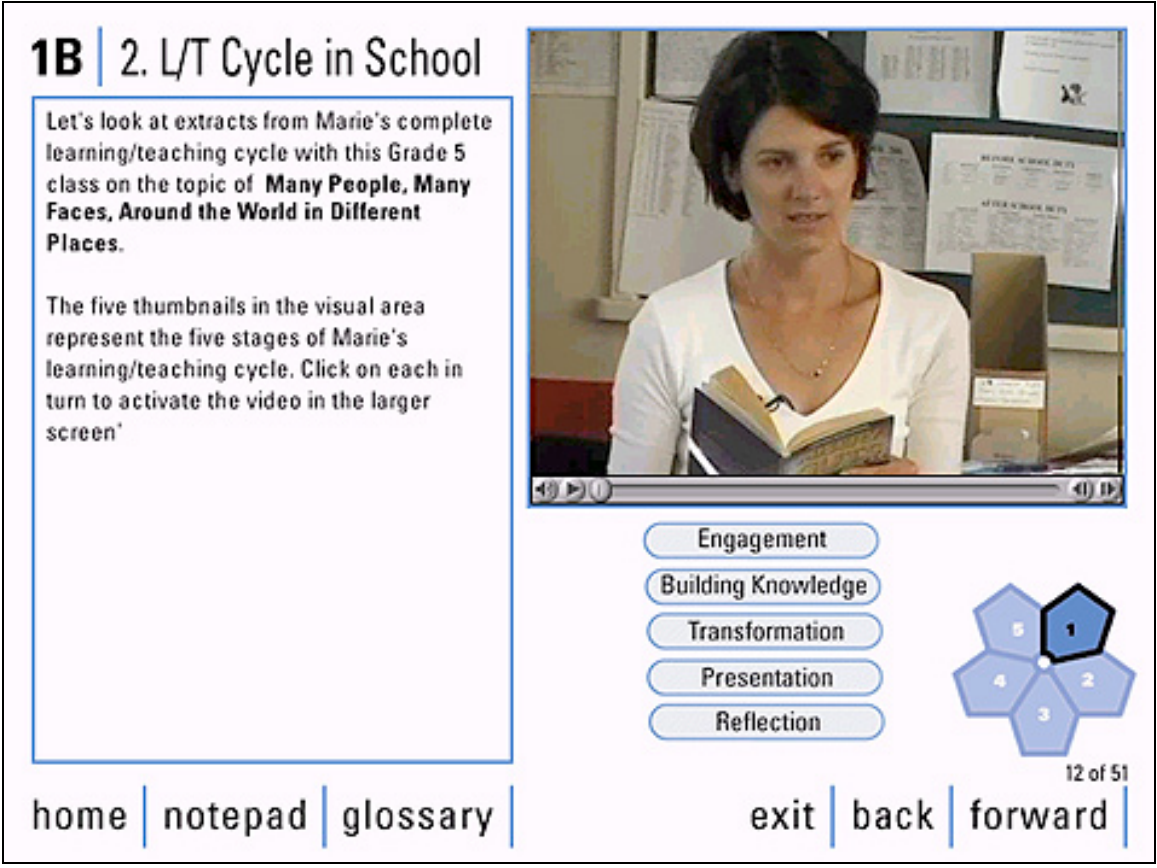

Screenshot 3: Learning/teaching cycle in school

Through the QuickTime videos, the QTVRs and the interactive tasks with authentic texts, this learning/teaching cycle was illustrated in a wide variety of classroom contexts, from early primary school to upper secondary, and across a range of Key Learning Areas. Users could choose to focus on material related to their own teaching area, although they were encouraged (both through the design of the CD-ROM and through the assessment tasks for the subject 'Language and Literacy in the Classroom') to explore other areas of the curriculum as antecedents, precedents or cooccuring with their own areas. In this way, developing teachers could recognise how learning/teaching cycles accumulated over the years and across the KLAs into a 'spiralling curriculum' (Bruner, 1986), through which learners were socialised into the knowledge, skills and values of our society.

\section{Scaffolding as multimedia architecture}

As well as providing a framework for the instructional content, the metaphor of scaffolding also underpins the instructional design of BUILT. The BUILT planning team took nearly as long to clarify the instructional design of the CD-ROM in ways that were compatible with a theoretically 
rigorous model of scaffolding as they did to film six full days of classroom activities, conduct and film the teacher interviews, select and log all film clips and write the instructional content. Yet this extensive planning was seen as efficient and fundamental to the principled design of an effective learning tool, primarily because the papers that were reviewed at this stage (in particular Herrington \& Oliver, 1995, 1997; McLoughlin et al, 2000; Winnips et al, 2000) worked to clarify principles of multimedia design that draw on the concepts of scaffolding, apprenticeship, internalisation of knowledge and the ZPD, as articulated by Bruner (1986) Vygotsky (1978) and Wood, Bruner \& Ross (1976) and principles of cognitive apprenticeship in situated learning (Brown, Collins and Duguid, 1989).

Of particular importance in the planning of the instructional design was Herrington and Oliver's (1995) paper which lists nine characteristics critical to the effectiveness of multimedia based on models of situated learning. In the remainder of this section, a brief overview will be provided of the design features of BUILT as an interactive multimedia resource that addresses these nine critical characteristics and thereby scaffolds preservice teachers into reflective understandings about the relationship between language, literacy and learning within the context of real world applications.

Because the principle of scaffolding underpinning the pedagogical content of BUILT is theoretically rigorous and applicable to all educational sectors, the five stages of the learning/teaching cycle described earlier as an important scaffolding device could be built into the design of the CD-ROM. In this way, users of BUILT are themselves moved recursively through these five stages of each learning/teaching cycle, as they are: engaged in issues of language, literacy and learning; helped to build knowledge in this new area; guided into transforming that new knowledge into understanding; provided with various means of presenting that new understanding; and provided with the means of reflecting on that new understanding. Thus, while they are learning about the principles of scaffolding children into learning through language and literacy, they are themselves scaffolded into new professional understandings as they go through the sequences of learning/teaching cycles which underpin the design of the CD-ROM.

Starting with engagement, as users are learning about the importance of, and strategies for, engaging their own students in new understandings, they are themselves recursively experiencing interactive tasks designed to engage them in various aspects of this professional understanding. An example might illustrate the point here. In Unit 3 of BUILT, users are scaffolded into understandings of how the structural and linguistic features 
of different text types (or genres) of writing are systematically, (albeit often unconsciously) selected to achieve distinctive social purposes (Derewianka, 1990). One of the engagement tasks here is to have users drag various sentence fragments on the topic of 'Frogs' into boxes under the headings of two written text types, 'Report' and 'Narrative'. Following this drag and drop activity, users can record in the notepad (and later discuss in workshop groups) the more conscious reasoning behind their allocations. In this way, developing teachers can bring their existing linguistic knowledge to an introductory reflective or analytical task. Thus, a number of the requirements of situated learning and scaffolding are met, in particular that: learners (in this case the 'apprentice' teachers) are provided with the means to articulate tacit knowledge so that it becomes explicit; and that teachers (in this case the teacher educators) are provided with a means of identifying learners' existing knowledge, including gaps in that knowledge, in order to plan appropriate strategies for moving preservice teachers (as learners) into a new ZPD.

In the Building Knowledge stage of the same learning/teaching cycle of Unit 3, apprentice teachers are provided with explicit information about the structures and linguistic features of a variety of text types. The multimedia screens here are typically more didactic in their purpose and more linear in their sequencing. The models of writing presented are actual student or teacher texts of the sort that users will encounter in either their primary or secondary school experience. Structural and linguistic features of these texts are animated or illustrated in eye catching ways to make new knowledge as vivid as possible. QuickTime video clips of authentic classroom interaction furthermore illustrate how teachers scaffold writing development, and provide models of 'expert' teaching practice around writing.

The most crucial characteristic of effective multimedia design within a situated learning model is that it provides an authentic context that reflects the way the knowledge will be used in real life (Herrington \& Oliver, 1995,1997). The real world activities depicted in the QuickTime video clips are those which take place in classrooms similar to those in which preservice teachers will be undertaking their practice teaching, illustrating as they do the frustrations and challenges faced by classroom teachers and their students, as well as their accomplishments. QuickTime video clips of interviews with the teachers provide models of planning and reflection that developing teachers can access and emulate as relevant, either before, during or after their own practice teaching. In these and many other ways, the design features of the various Building Knowledge stages of the CD meet two of Herrington \& Oliver's (1995) conditions, providing access to expert performances and the modelling of processes, and authentic contexts reflecting the way that knowledge will be used in real life. 
In the Transformation stage of the same learning/teaching cycle of Unit 3 of BUILT, users are provided with opportunities to rehearse their new found knowledge about the structure and linguistic features of various text types and to internalise understandings according to their own needs. Further examples of authentic written texts are provided here for users to work on interactively, either through drag and drop, self correcting exercises, or through notepad activities that can be shared in pairs or workshops. Activities in this Transformation stage were designed to control the possibilities of user error, and to provide resources such as hyperlinked explanations, a Glossary, and a Bibliography that users could draw on independently as they transform newly acquired information into understanding. Through each of these design features of the Transformation stage, apprentice teachers are scaffolded into increasingly more independent understandings of the linguistic and structural features of various text types. They can access these features of BUILT again, either as they prepare to teach their own students to write a particular text type, or as they reflect on how they went about helping their students to write. In this way, the multimedia resource again meets a key condition for scaffolding and for situated learning (Brown, Collins and Duguid, 1989; Herrington and Oliver 1995).

The fourth stage of the learning/teaching cycle that apprentice teachers experience through the design of the CD-ROM is the Presentation stage. Remaining for illustrative purposes with the same cycle from Unit 3, in these screens users are provided with the opportunity to demonstrate, both formally and informally, their independent understandings of the structure and linguistic features of particular text types. Formal presentation for example occurs as users are invited to copy a sample text from the screen into their notepads, where they can identify its key structural and linguistic features and discuss which of the modelling strategies demonstrated in previous QuickTime video clips they would use to scaffold students into similar forms of writing in their own teaching areas. A selection of these more formal, but nonetheless situated tasks constituted the assessment tasks for the subject 'Language and Literacy in the Classroom' in 2001. Through such design features, BUILT is meeting Herrington and Oliver's (1995) condition that scaffolding within a situated learning model further enable tacit knowledge to be made explicit and that assessment of user learning be integrated with the tasks.

The final stage of the learning/teaching cycle that developing teachers experience through the design of the CD-ROM is the Reflection stage. This is a particularly important stage in teacher education, since it is here that apprentice teachers are able to evaluate the effectiveness of the teaching, the relevance of their learning, the problems or challenges and their own teaching goals (Schon, 1983). In becoming aware of these processes in their 
own learning they will presumably be more attentive to their significance in their classroom teaching. Regular smaller reflective tasks are thus built carefully into the design of the CD-ROM, typically at the end of each learning/teaching cycle, and typically asking users to respond to broad prompt questions in their notepads. However larger reflective tasks also occur at the end of each Unit, requiring users to review all notepad entries for that Unit, and feeding into workshop or assessment reflections.

By incorporating the 5 stages of the learning/teaching cycle into the design of BUILT as a multimedia resource, the designers have scaffolded users in three complementary ways, each of which fulfils the conditions of true scaffolding in situated learning. Firstly, developing teachers have been scaffolded into disciplinary understandings about the structures and functions of oral and spoken language and their relationship to learning. Secondly they have been scaffolded into insights about how to apply knowledge of these structures and functions in their own teaching context. Thirdly they have been scaffolded through the design of BUILT as an interactive multimedia resources which operates recursively (and in a principled way) through the 5 stages of its own learning/teaching cycles.

\section{Evaluation}

The end of semester Quality of Teaching Questionnaire (a University mandated quality control instrument) indicated that BUILT was instrumental in helping students achieve the outcomes of the subject 'Language and Literacy in the Classroom' as identified above. A more targeted and extensive evaluation of BUILT was conducted with the 800 students enrolled in the core subject 'Language and Literacy in the Classroom' in 2001. This formal evaluation was conducted through questionnaires issued to all students and follow up interviews with selected students (Shrimpton \& Love, 2001). Results indicated that as well as being able to use the resource effectively to achieve the intended learning outcomes specified earlier in this paper, users recognised the value of the CD-ROM in providing opportunities for them to work interactively with authentic examples of language and literacy used in teaching, within a strongly theorised framework.

The most significant issue arising out of this first formal evaluation of BUILT however was the reassurance that most of this cohort of apprentice teachers, even after a relatively short 18 hour introductory and generalist course, clearly understood the model of scaffolding that was theorised, through the five stage learning/teaching cycle, to underpin effective teaching. At the level of instructional design too, these apprentice teachers offered feedback which indicated that they had also recognised how this same learning teaching cycle had been used as design architecture to scaffold their own understandings of language, literacy and learning. 
The formal evaluation also elicited useful perceptions concerning the effectiveness of the way in which BUILT was integrated into lectures, workshops and assessment tasks. A particular concern related to the integration of the CD-ROM with the assessment tasks and with the amount of work required in an 18 hour subject. Recommendations arsing from this formal evaluation will further inform the planning around the implementation of the resource in subsequent years. Clearly, issues to do with the design of BUILT as a multimedia resource need to be considered hand in hand with planning for its implementation in specific contexts.

Most importantly, the formal evaluation also elicited useful recommendations for redesign features in the next version of BUILT. The second edition of BUILT (2002) includes a hyperlinked table of contents, which makes explicit the hierarchical nature of the hypermedia linking structure (Oliver \& Herrington, 1995) and provides users with a 'map' of the contents. The division of the resource into 4 Units, each with 2 topics, allows it to fit neatly into the nine week course structure of the generalist 'Language and Literacy in the Classroom' subject. This group of preservice teachers worked only with key concepts (related to text structuring, linguistic knowledge and scaffolding learning through language) at the most immediate level of the hierarchy. Beyond this initial or 'macro' level, more sophisticated exploration of the same key concepts can be engaged in at a deeper or more 'delicate' level of analysis with the CD-ROM. Such exploration was possible within the 8 semester literacy based sequence of the four year Bachelor of Education program. The deliberate choice of a hierarchical hypermedia structure for BUILT over either a linear or referential structure (Oliver \& Herrington, 1995) was based on the need to develop a multimedia resource that would allow for both width and depth in more advanced and specialised programs such as the Bachelor of Education. The hyperlinked table of contents allows staff and students in the four year program to select from the more demanding levels of a resource which is sufficiently flexible in its structure and comprehensive in its content.

Another feature developed in the second edition as an outcome of the formal evaluation was a 'Go To' function. This function also allows users with different levels of prior knowledge and different needs to explore the resource for specific information at point of need, either prior to, during or after practice teaching. This function, along with the hyperlinked table of contents, has proven particularly useful with another cohort of BUILT users, experienced teachers seeking professional development regarding language and literacy. Feedback from literacy consultants who are using BUILT in a professional development capacity have already indicated that the hyperlinked table of contents (with its hierarchical and modular organisation and its exploration of language and learning at various levels 
of difficulty or delicacy) and the 'Go To' function provides them with a set of clear pathways to select from as they meet the needs of different teachers in different contexts.

BUILT has also been used as a core resource in preservice courses in overseas teacher training institutions, most significantly the Bachelor of Education (English for Young Learners) programs in the United Arab Emirates and in Malaysia. Course coordinators in these international contexts have reported that the functional model of language underpinning the resource accounts adequately for the language and learning contexts in which their preservice teachers are working, and that the metaphor of scaffolding is sufficiently principled, both as an instructional concept and as a design feature, to apply to learning and teaching in their cultural contexts. However, no formal evaluation of the use of BUILT in these contexts has yet been conducted. Its designers look forward to testing the depth of BUILT's transferability in these other cultural contexts.

\section{References}

Brown, J.S., Collins, A. \& Duguid, P. (1989). Situated cognition and the culture of learning. Educational Researcher, 18, 32-42.

Bruner, J. (1986). Actual Minds, Possible Worlds. Cambridge, Mass: Harvard University Press.

Christie, F., Devlin, B., Freebody, P., Luke, A., Martin, J., Threadgold, T. \& Walton, C. (1991). Teaching English Literacy: A project of national significance on the preservice preparation of teachers for teaching English literacy. Centre for Studies of Language in Education, Darwin University.

Derewianka, B. (1990). Exploring How Texts Work. PETA Newton, NSW.

Derewianka, B. (1998). A Grammar Companion. PETA Newton, NSW.

Edwards D. \& Mercer, N. (1987). Common Knowledge: The development of understanding in the classroom. Methuen, London.

Halliday, M.A.K (1973). Explorations in the Functions of Language. London: Edward Arnold.

Halliday, M.A.K (1994). An Introduction to Functional Grammar. London: Edward Arnold.

Hammond, J. (Ed) (2001). Scaffolding Teaching and Learning in Language and Literacy Education. Primary English Teachers Association (NSW).

Herrington, J. \& Oliver, R. (1995). Critical characteristics of situated learning: Implications for the instructional design of multimedia. In J. Pearce \& A. Ellis (Eds) Learning with Technology. (pp 235-262). Melbourne: University of Melbourne. 
Herrington, J. \& Oliver, R. (1997). Multimedia, magic and the way students respond to a situated learning environment. Australian Journal of Educational Technology, 13(2), 127-143. http:// www.ascilite.org.au/ajet/ajet13/herrington.html

Kramsch, C. (1998). Language and Culture. Oxford: Oxford University Press.

Lave, J. \& Wengler, E. (1991) Situated Learning: Legitimate Peripheral Participation. Cambridge: Cambridge University Press.

Love, K., Pigdon, K. \& Baker, G. (2001). Building Understandings in Literacy and Teaching (CD-ROM). The University of Melbourne. Demonstration at http:/ / www.edfac.unimelb.edua.au/LLAE/BUILT

Love, K., Pigdon, K. \& Baker, G. (2002). Building Understandings in Literacy and Teaching:Second Edition (CD-ROM). The University of Melbourne. Demonstration at http: / / www.edfac.unimelb.edua.au/LLAE/BUILT

Maybin, J., Mercer, N. \& Stierer, B. (1992). Scaffolding learning in the classroom. In Norman, K (ed) Thinking Voices: The work of the National Curriculum Project. London: Hodder and Stoughton for the National Curriculum Council.

McLoughlin, C., Winnips, J.C. \& Oliver, R. (2000). Supporting constructivist learning through learner support online. EDMEDIA 2000 (June).

Mercer, N. (1994). Neo-Vygotskian theory and classroom education. In B. Stierer \& J. Maybin (Eds), Language, Literacy and Learning in Educational Practice. Clevedon, UK: Multilingual Matters.

Oliver, R. \& Herrington, J. (1995). Developing effective hypermedia instructional materials. Australian Journal of Educational Technology, 11(2), 8-22. http: / / www.ascilite.org.au/ajet/ajet11/oliver.html

Schon, D (1983). The Reflective practitioner: How Professionals Think in Action. New York: Basic Books.

Sheely, S., Veness, D. \& Rankine, L. (2001). Building the Web Interactive Study Environment: Mainstreaming online teaching and learning at the University of Western Sydney. Australian Journal of Educational Technology, 17(1), 80-95. http: / / www.ascilite.org.au/ajet/ajet17 / sheely.html

Shrimpton, B. \& Love, K. (2001). Evaluating BUILT, a multimedia resource used by preservice teachers with different needs. University of Melbourne Internal Report.

Vygotsky, L. (1978). Mind in Society: The development of higher psychological processes. Cambridge MA: Harvard University Press.

Winnips, K., Collis, B. \& Moonen, J. (2000). Implementing a 'scaffolding by design' model in a WWW-based course considering cost and benefits. Proceedings of the Ed Media Conference.

Wood, D., Bruner, J. \& Ross, G. (1976). The role of tutoring in problem solving Journal of Child Psychology and Psychiatry, 17. 